\title{
Biosynthesis of dihydroquercetin in Escherichia coli from
}

\section{glycerol} (1)

6 a Metabolic and Biomolecular Engineering National Research Laboratory, Systems Metabolic Engineering and Systems Healthcare Cross Generation Collaborative Laboratory, Department of Chemical and Biomolecular Engineering (BK21 Plus Program), Institute for the BioCentury, Korea Advanced Institute of Science and Technology (KAIST), 291 Daehak-ro, Yuseong-gu, Daejeon 34141, Republic of Korea.

11

${ }^{b}$ BioProcess Engineering Research Center, KAIST, 291 Daehak-ro, Yuseong-gu, Daejeon 34141, Republic of Korea.

${ }^{\mathrm{c} B i o I n f o r m a t i c s ~ R e s e a r c h ~ C e n t e r, ~ K A I S T, ~} 291$ Daehak-ro, Yuseong-gu, Daejeon 34141, Republic of Korea.

*Corresponding author at: Metabolic and Biomolecular Engineering National Research Laboratory, Department of Chemical and Biomolecular Engineering, BioProcess Engineering Research Center, BioInformatics Research Center, and Institute for the BioCentury, KAIST, 291 Daehak-ro, Yuseong-gu, 34141 Daejeon, Republic of Korea.

\section{E-mail address: leesy@kaist.ac.kr(S.Y.Lee).}

${ }^{1}$ These authors contributed equally to this work.

${ }^{2}$ Current address: Efficacy. Fermentation Research Team, LG Household \& Healthcare, 70, Magokjungang 10-ro, Gangseo-gu, Seoul 


\section{Abstract}

Phenylpropanoids are a group of diverse natural products derived from aromatic amino acids. Although their demands are high both as drugs and nutraceuticals, their production mainly depends on inefficient extraction from plants. To achieve sustainable production of phenylpropanoids, engineering model microorganisms such as Escherichia coli has been sought, but most strains require supplementation of expensive precursors. Here, we report one-step production of a representative phenylpropanoid, dihydroquercetin (DHQ), from simple carbon sources in $E$. coli for the first time. The best DHQ producer strain capable of producing 239.4 $\mathrm{mg} / \mathrm{L}$ of DHQ from glycerol was obtained by optimizing the biosynthetic pathway and engineering the signal peptide of cytochrome P450 (TT7) from Arabidopsis thaliana. The engineered plant P450 could produce a significantly higher titer of DHQ than a bacterial monooxygenase, showing the potential of employing plant P450s for the production of diverse natural products that has been previously difficult in bacterial hosts. This study will serve as a guideline for industrial production of pharmaceutically important yet complex natural products.

40 Keywords: Metabolic engineering; Dihydroquercetin; Escherichia coli. 


\section{Introduction}

Phenylpropanoids span a diverse group of plant secondary metabolites derived from aromatic amino acids (Dey, 2016). These natural products are biologically active since they perform essential functions for plant survival and reproduction such as defence against pathogens, pests, or animals and attracting insect pollinators. Therefore, many phenylpropanoids are also reported to be beneficial for human health, showing diverse pharmaceutical activities such as antioxidant, antitumor, anti-inflammatory, antidiabetic, antiviral, and anti-bacterial properties (Dey, 2016). DHQ (also known as taxifolin) possesses various pharmacological activities including anticancer, antioxidant, chemopreventive, antimelanogenesis, and anti-Alzheimer's effects (An et al., 2008; Lee et al., 2007; Sato et al., 2013; Sunil and $\mathrm{Xu}, 2019$ ), and is included in a number of nutraceuticals or drugs such as Legalon ${ }^{\circledR}$ or Pycnogenol ${ }^{\circledR}$ (Sunil and Xu, 2019; Yang et al., 2020b). DHQ also is an important precursor for the production of more complex flavonolignans such as silybin and isosilybin which are found from the seed of Milk Thistle (Silybum marianum) (Bijak, 2017; Gazak et al., 2007; Mengs et al., 2012; Deep et al., 2007).

Despite rising demands for these phenylpropanoids due to their versatile applications, their supply has been limited by unstable, toxic, and inefficient extraction from the plants. Nevertheless, this inefficient process has been the sole method for commercial production of phenylpropanoids, leading to their high prices in the market. In this regard, metabolic engineering has been an attractive solution for efficient and sustainable production of valuable natural products from model microorganisms such as Escherichia coli and Saccharomyces cerevisiae. Various tools and strategies developed for metabolic engineering have enabled successful production of various important natural products by microorganisms, with the stateof-the-art examples of cannabinoids (Luo et al., 2019), tropane alkaloids (Srinivasan and Smolke, 2020), and astaxanthin (Park et al., 2018), to list a few. Microbial production of DHQ 
66 from glucose was recently achieved by Yarrowia lypotica $(110.5 \mathrm{mg} / \mathrm{L})(\mathrm{Lv}$ et al., 2019a) and

67 by $S$. cerevisiae (336.8 mg/L) (Yang et al., 2020b), but bacterial production of DHQ from simple carbon sources has not yet been achieved.

In this paper, we report one-step de novo production of a representative phenylpropanoid, DHQ, from glycerol by recombinant E. coli. An E. coli strain capable of producing high level of DHQ was developed and optimized by biosynthetic pathway optimization, plant P450 engineering, and fermentation condition optimization. This study will serve as an important guideline by providing essential metabolic engineering strategies for industrial production of pharmaceutically important yet complex natural products.

\section{Materials and Methods}

\subsection{Materials and strains}

Eriodictyol, dihydrokaempferol (DHK), and DHQ were purchased from Merck (Sigma Aldrich). p-Coumaric acid and naringenin were purchased from Tokyo Chemical Industry. TT7 (codon optimized for E. coli) was synthesized as gBlocks Gene Fragment from Integrated DNA

81 Technologies Inc. The ATR2 gene (codon optimized for E. coli) was synthesized from GenScript. All strains and plasmids used in this study are listed in Table 1 and 2, respectively. was used as a host strain for the production of all phenylpropanoids. 
Standard protocols were used for PCR, gel electrophoresis and transformation experiments (Sambrook, 1989). The plasmids and oligonucleotides used in this study are listed in Table 2 and 3, respectively. E. coli DH5 (Invitrogen) was used as a host strain for routine gene cloning, in Luria-Bertani (LB) medium (per liter: $10 \mathrm{~g}$ tryptone, $5 \mathrm{~g}$ yeast extract and 10 $\mathrm{g} \mathrm{NaCl}$ ) or on $\mathrm{LB}$ agar plates at $37{ }^{\circ} \mathrm{C}$ supplemented with appropriate concentrations of antibiotics when necessary: $50 \mu \mathrm{g} / \mathrm{mL}$ of kanamycin, $100 \mu \mathrm{g} / \mathrm{mL}$ of ampicillin, $100 \mu \mathrm{g} / \mathrm{mL}$ of spectinomycin, and/or $17 \mu \mathrm{g} / \mathrm{mL}$ of chloramphenicol. Polymerases used for PCR reactions were either Lamp-Pfu or Pfu purchased from Biofact (Daejeon, Republic of Korea). Restriction endonucleases were purchased from either Enzynomics (Daejeon, Republic of Korea) or NEB (Ipswich, MA).

To test the conversion of naringenin to DHK, plasmid pTac15K-F3H was constructed by PCR amplification of $F 3 H$ from the cDNA of $A$. thaliana using primers F3H_F_EcoRI and F3H_R_SacI and inserting the amplified gene fragment to pTac15K at the EcoRI and SacI sites. pTrc99A-F3H was constructed using the same method. Then, the $F 3 H$ gene was PCR amplified amplified gene fragment was inserted into pNRG by Gibson assembly at PstI site to construct pDHK.

For the production of DHQ, TT7 and ATR2 from A. thaliana codon-optimized for expression in E. coli were synthesized (Integrated DNA Technologies Inc.). Plasmid pTrc99ATT7 was constructed by PCR amplification of TT7 from the artificially synthesized TT7 gene fragment using primers TT7_F_BamHI and TT7_R_SalI followed by insertion to pTrc99A at BamHI and SalI sites. For the construction of pTrc99A-trTT7, trTT7 was PCR amplified from the synthetic TT7 using primers trTT7_F_BamHI and TT7_R_SalI and inserted to pTrc99A at the same sites. pTrc99A-SPtrTT7 was also constructed by PCR amplification of SPtrTT7 from 
the synthetic TT7 and inserting the amplified gene fragment to pTrc99A at the same sites. Here, SPtrTT7 was first amplified using primers SP_F2_over and TT7_R_SalI, and then extended by PCR using primers SP_F1_BamHI and TT7_R_SalI. For the construction of pTac15K-ATR2 and pDHQ, ATR2 was PCR amplified from the synthetic ATR2 using primers ATR2_F_EcoRI and ATR2_R_BamHI, and was inserted to pTac15K and pTrc99A-SPtrTT7, respectively, both at EcoRI and BamHI sites. To construct pDHQ2, DNA fragment containing ATR2 and SPtrTT7 was PCR amplified from pDHQ using primers ATR2_F_SacI and TT7_R_XbaI, and was inserted into $\mathrm{pBBR} 1 \mathrm{TaC}$ at SacI and XbaI sites.

\subsection{Media and culture conditions}

Strains for the production of all phenylpropanoids were first inoculated from colonies on LB agar plates into $25 \mathrm{~mL}$ test tubes containing $10 \mathrm{~mL}$ of LB medium supplemented with appropriate antibiotics, and were cultivated in a rotary shaker at $220 \mathrm{rpm}$, at $37^{\circ} \mathrm{C}$ for $12-16 \mathrm{~h}$. Then, $1 \mathrm{~mL}$ aliquot of each seed culture was transferred to a $250 \mathrm{~mL}$ baffled flask containing $50 \mathrm{~mL}$ of minimal medium (MR) and was incubated at $30{ }^{\circ} \mathrm{C}$ and at $200 \mathrm{rpm}$. For the production of DHQ, $2 \mathrm{~g} / \mathrm{L}$ of yeast extract, $20 \mathrm{~g} / \mathrm{L}$ of glycerol, and $3 \mathrm{~g} / \mathrm{L}$ of $\left(\mathrm{NH}_{4}\right)_{2} \mathrm{SO}_{4}$ was supplemented. The MR medium ( $\mathrm{pH}$ 6.8) contains the followings per liter: $6.67 \mathrm{~g} \mathrm{KH}_{2} \mathrm{PO}_{4}, 4 \mathrm{~g}\left(\mathrm{NH}_{4}\right)_{2} \mathrm{HPO}_{4}$, $0.85 \mathrm{~g}$ citric acid, $0.8 \mathrm{~g} \mathrm{MgSO}_{4} \cdot 7 \mathrm{H}_{2} \mathrm{O}$, and $5 \mathrm{~mL}$ TMS. The TMS contains the followings per liter of $5 \mathrm{M} \mathrm{HCl}: 10 \mathrm{~g} \mathrm{FeSO}_{4} \cdot 7 \mathrm{H}_{2} \mathrm{O}, 2.25 \mathrm{~g} \mathrm{ZnSO}_{4} \cdot 7 \mathrm{H}_{2} \mathrm{O}, 1 \mathrm{~g} \mathrm{CuSO}_{4} \cdot 5 \mathrm{H}_{2} \mathrm{O}, 0.5 \mathrm{~g} \mathrm{MnSO}_{4} \cdot 5 \mathrm{H}_{2} \mathrm{O}$, $0.23 \mathrm{~g} \mathrm{Na}_{2} \mathrm{~B}_{4} \mathrm{O}_{7} \cdot 10 \mathrm{H}_{2} \mathrm{O}, 2 \mathrm{~g} \mathrm{CaCl}_{2} \cdot 2 \mathrm{H}_{2} \mathrm{O}$ and $0.1 \mathrm{~g}\left(\mathrm{NH}_{4}\right)_{6} \mathrm{Mo}_{7} \mathrm{O}_{24}$ (Jeong and Lee, 2002). When the $\mathrm{OD}_{600}$ of the cultures reached $1-2,1 \mathrm{mM}$ isopropyl $\beta$-D-1-thiogalactopyranoside (IPTG) was added to induce heterologous gene expression. When required, $50 \mathrm{mg} / \mathrm{L}$ of kanamycin $(\mathrm{Km}), 100 \mathrm{mg} / \mathrm{L}$ of ampicillin $(\mathrm{Ap}), 17 \mathrm{mg} / \mathrm{L}$ of chloramphenicol $(\mathrm{Cm})$ and/or 100 
$\mathrm{mg} / \mathrm{L}$ of spectinomycin (Spc) was added to the medium. After induction, the cells were cultivated for 48 hours.

\subsection{Fed-batch fermentation}

Fed-batch fermentations for DHQ production were conducted in a $5 \mathrm{~L}$ jar fermenter (MARADO-05D-PS, CNS, Daejeon, Republic of Korea) containing 2 L of R/2 medium supplemented with $2 \mathrm{~g} / \mathrm{L}$ yeast extract, $20 \mathrm{~g} / \mathrm{L}$ glycerol, and $3 \mathrm{~g} / \mathrm{L}$ of $\left(\mathrm{NH}_{4}\right)_{2} \mathrm{SO}_{4}$. When required, $50 \mathrm{mg} / \mathrm{L}$ of $\mathrm{Km}, 100 \mathrm{mg} / \mathrm{L}$ of Ap, $17 \mathrm{mg} / \mathrm{L}$ of $\mathrm{Cm}$ and/or $100 \mathrm{mg} / \mathrm{L}$ of $\mathrm{Spc}$ was added to the medium. Strains were first inoculated from colonies on LB agar plates into $25 \mathrm{~mL}$ test tubes each containing $10 \mathrm{~mL}$ of LB medium supplemented with appropriate antibiotics, and were cultivated in a rotary shaker at $220 \mathrm{rpm}$, at $37^{\circ} \mathrm{C}$ overnight $(12-16 \mathrm{~h})$. Then, $1 \mathrm{~mL}$ aliquot of each seed culture was transferred to a $250 \mathrm{~mL}$ baffled flask containing $50 \mathrm{~mL}$ of minimal medium supplemented with $2 \mathrm{~g} / \mathrm{L}$ yeast extract, $20 \mathrm{~g} / \mathrm{L}$ glycerol, and $3 \mathrm{~g} / \mathrm{L}$ of $\left(\mathrm{NH}_{4}\right)_{2} \mathrm{SO}_{4}$. After incubation at $37{ }^{\circ} \mathrm{C}$ shaken at $220 \mathrm{rpm}$ until the $\mathrm{OD}_{600}$ value reached $3 \sim 4,50 \mathrm{~mL}$ of the seed culture was inoculated into the bioreactor containing the medium saturated by filtered air. The culture $\mathrm{pH}$ was controlled at 6.8 using 28\% (v/v) ammonia solution (Junsei Chemical, Japan). The dissolved oxygen (DO) level of the culture was maintained at $40 \%$ of air saturation by supplying air at $2 \mathrm{~L} / \mathrm{min}$ and automatically increasing the agitation speed from $200 \mathrm{rpm}$ up to $1000 \mathrm{rpm}$ and by changing the percentage of pure oxygen added. The $\mathrm{pH}$-stat feeding strategy was employed in order to supply exhausted nutrients to the fermenter. The feeding solution 
contains the followings per liter: $800 \mathrm{~g}$ glycerol, $12 \mathrm{~g} \mathrm{MgSO} \cdot 7 \mathrm{H}_{2} \mathrm{O}, 40 \mathrm{~g}\left(\mathrm{NH}_{4}\right)_{2} \mathrm{SO}_{4}$, and 6 $\mathrm{mL}$ TMS. When $\mathrm{pH}$ becomes higher than 6.85 due to carbon source exhaustion, the feeding solution was automatically added. To induce heterologous gene expression, $1 \mathrm{mM}$ of IPTG was added when the $\mathrm{OD}_{600}$ of the culture reached 20 30.

\subsection{Analytical procedures}

After shake flask or fed-batch culture, cells were harvested by centrifugation at 16,000 $g$ for $2 \mathrm{~min}$. For the analysis of naringenin, eriodictyol, DHK, and DHQ, culture supernatant was extracted with an equal volume of ethyl acetate, and was vortexed vigorously using Thermo shaker (TS100, Ruicheng) for $10 \mathrm{~min}$ at $40{ }^{\circ} \mathrm{C}, 1500 \mathrm{rpm}$. The extracted ethyl acetate portion was dried and re-solubilized in methanol. The prepared samples were analyzed with high-performance liquid chromatography (HPLC; 1260 Infinity II; Agilent) equipped with DAD detectors (G7115A; Agilent) and a C18 column (Poroshell 120 EC-C18 column; $4.6 \times$ $150 \mathrm{~mm}$; Agilent). The mobile phase consists of A ( $0.1 \%$ trifluoroacetic acid) and solvent B (acetonitrile) was run at a flow rate of $0.6 \mathrm{~mL} / \mathrm{min}$. The following gradient was applied: $0-3$ min, an isocratic condition at 5\% B; $3-20$ min, a linear gradient of solvent B from $5 \%$ to $70 \%$; 20-25 min, an isocratic condition at 70\% B (all in vol\%). Samples were monitored at $220 \mathrm{~nm}$ (DHK and DHQ) or $330 \mathrm{~nm}$ (p-coumaric acid, eriodictyol, and naringenin). Concentrations of each product was determined by mapping the area of HPLC peaks to each calibration curve generated using dilutions of authentic chemicals.

DHQ produced by engineered E. coli strains from glycerol were further analyzed through HPLC (1100 Series HPLC; Agilent) connected with MS (LC/MSD VL; Agilent) and by comparing with the mass spectrum of the commercially available authentic standard 
chemicals. For DHQ, $1 \mathrm{~mL}$ of the culture supernatant was extracted with equal volume of ethyl acetate, dried, and re-solubilized in equal volume of methanol. XBridge C18 column ( $4.6 \times$ $150 \mathrm{~mm}$; Waters) was used and operated at $25^{\circ} \mathrm{C}$. For DHQ, two mobile phase solvents were used: solvent A (20 mM ammonium acetate, $\mathrm{pH} 9.6)$ and solvent B (acetonitrile). The total flow rate was maintained at $0.4 \mathrm{~mL} / \mathrm{min}$, and the following gradient was applied: $0-3 \mathrm{~min}, 5 \%$ solvent B; 3-15 min, a linear gradient of solvent B from 5\% to 70\%; $15-20$ min, a linear gradient of solvent B from 70\% to 90\%; 20-30 min, an isocratic condition at 90\% solvent B (all in vol\%).

The eluent was continuously injected into the mass spectrometry using ESI negative ion mode with the following conditions: fragmentor, $160 \mathrm{~V}$; drying gas flow, $12.0 \mathrm{~L} / \mathrm{min}$; drying gas temperature, $350^{\circ} \mathrm{C}$; nebulizer pressure, $30 \mathrm{psig}$; capillary voltage, $5.5 \mathrm{kV}$. For analysis, scan mode was used. For LC-MS, the scanned mass range was $m / z$ of 130-300.

\subsection{SDS-PAGE analysis}

To confirm the expression of heterologous enzymes, E. coli BL21(DE3) strains harboring the respective recombinant plasmids were first cultured in $10 \mathrm{~mL}$ test tubes containing R/2 medium supplemented with $2 \mathrm{~g} / \mathrm{L}$ yeast extract, $20 \mathrm{~g} / \mathrm{L}$ glycerol, and appropriate antibiotics. The cells were grown at $30^{\circ} \mathrm{C}$ and were induced with $1 \mathrm{mM}$ IPTG when the $\mathrm{OD}_{600}$ of the culture reached 0.4-0.6. After additional cultivation for 6-10 hr, cells were collected (i.e., $3 \mathrm{~mL}$ of cells when their $\mathrm{OD}_{600}$ reached 1.0) by centrifugation at $15,000 \mathrm{~g}$ for $1 \mathrm{~min}$ at $4{ }^{\circ} \mathrm{C}$. Cell pellets were washed with $1 \mathrm{~mL}$ of cold phosphate-buffered saline (PBS) solution (pH 7.4), centrifuged at $15,000 \mathrm{~g}$ for $1 \mathrm{~min}$ at $4{ }^{\circ} \mathrm{C}$, and resuspended in $0.3 \mathrm{~mL}$ of the same buffer. The resuspended cells were lysed by sonication (High-Intensity Ultrasonic Liquid Processors, Sonics \& Materials Inc., Newtown, CT). To precipitate insoluble protein fractions and partially disrupted cells, the sonicated samples were centrifuged at $15,000 \mathrm{~g}$ for $10 \mathrm{~min}$ at $4{ }^{\circ} \mathrm{C}$. Crude 
cell lysates were used for total protein expression analysis and the supernatants were used for soluble protein expression analysis.

\subsection{Statistical analysis}

We did not predetermine sample sizes. All colonies were randomly selected from plates containing 100-200 colonies and subject to independent flask culture and chemical analysis. All numerical data are presented as mean $\pm \mathrm{SD}$ (standard deviation) from experiments done in duplicates or triplicates. The investigators were blinded to the group allocation by randomly selecting single colonies multiple times.

\section{Results and discussion}

DHQ is produced from $p$-coumaric acid. In S. cerevisiae, one-step de novo production of $336.8 \mathrm{mg} / \mathrm{L}$ of DHQ from glucose was reported (Lv et al., 2019a). However, in E. coli, production of DHQ has been achieved only by supplying expensive precursors (e.g., L-tyrosine, $p$-coumaric acid). We previously reported the construction of a recombinant E. coli strain capable of producing $103.8 \mathrm{mg} / \mathrm{L}$ of naringenin from glycerol (Yang et al., 2018). The naringenin producer employed tyrosine-ammonia lyase (TAL) from S. espanaensis, a mutant 4-coumarate:CoA ligase $1(4 \mathrm{CL} 1 \mathrm{~m})$ from $A$. thaliana, chalcone isomerase (CHI) from $A$. thaliana, and chalcone synthase (CHS) from Petunia $x$ hybrida to enable the conversion of Ltyrosine to naringenin (Fig. 1). As naringenin is a precursor of DHQ, the naringenin producer [BTY5 harboring pCOU and pNRG (harboring 4CL1m, $C H I$, and $C H S$ )] was used for de novo DHQ production. 
Production of DHQ from naringenin can be achieved via either eriodictyol or dihydrokaempferol (DHK) (Fig. 1). Conversion of naringenin to DHK was first tested. Flavanone 3-hydroxylase ( $\mathrm{F} 3 \mathrm{H})$ from $A$. thaliana was reported to convert either naringenin into DHK or eriodictyol into DHQ (Owens et al., 2008). Introduction of F3H into E. coli BL21(DE3) resulted in $170.4 \mathrm{mg} / \mathrm{L}$ of DHK production from $500 \mathrm{mg} / \mathrm{L}$ of naringenin (Fig. 1A). Next, a flavonoid 3'-hydroxylase (TT7) from A. thaliana, which is a cytochrome P450 (simply P450 henceforth), was employed to convert naringenin into eriodictyol or DHK into DHQ (Schoenbohm et al., 2000). As a P450 monooxygenase requires co-expression of a P450 reductase as its redox partner, a P450 reductase from $A$. thaliana (ATR2) was also employed (Niu et al., 2017). Plasmids pTrc99A-TT7 and pTac15K-ATR2 were constructed and transformed into E. coli BL21(DE3), followed by flask culture. However, conversion of naringenin into eriodictyol was not observed (Fig. 1B). By contrast to bacterial P450s, plant P450s are bound to subcellular organelles [i.e., endoplasmic reticulum (ER)], guided by Nterminal signal peptides. In this regard, a TT7 variant truncated with its N-terminal signal peptide (trTT7) was constructed for cytoplasmic expression in E. coli. To mimic the mode of action of plant P450s, we also tested guiding the enzyme to the inner membrane by construction of SPtrTT7 (a TT7 variant with its N-terminal signal peptide exchanged with that of $E$. coli OmpA). Activity of the P450 enzyme was only observed when SPtrTT7 was employed, producing $19.7 \mathrm{mg} / \mathrm{L}$ of eriodictyol from $100 \mathrm{mg} / \mathrm{L}$ of naringenin (Fig. 1B). Such drastic enhancement of enzyme activity can be attributed to two reasons as follows: (1) the membranebound SPtrTT7 and ATR2 would have been properly oriented which is favorable for the enzymatic reactions, (2) exchanging the $\mathrm{N}$-terminal tag enhanced enzyme expression as identified by SDS-PAGE analysis (Fig. 2A). Next, to test whether co-expression of F3H and 
(harboring ATR2 and SPtrTT7) were introduced into E. coli BL21(DE3), successfully producing $28.5 \mathrm{mg} / \mathrm{L}$ of DHQ from $100 \mathrm{mg} / \mathrm{L}$ of naringenin (Fig. 1C).

To test a non-P450 enzyme - which was expected to be more favorable than P450 in E. coli-for DHQ production, E. coli hpaBC was tested for its ability to convert naringenin to eriodictyol (Jones et al., 2016b). E. coli BL21(DE3) harboring pTac15K-F3H and pCAF (harboring E. coli $h p a B C$ ) was cultured, and $13.6 \mathrm{mg} / \mathrm{L}$ of DHQ was produced from $100 \mathrm{mg} / \mathrm{L}$ of naringenin (Fig. 2B). The DHQ titer (13.6 mg/L) was significantly lower than that $(28.5$ mg/L) obtained by employing SPtrTT7. In addition, higher accumulation DHK (37.4 mg/L) than that obtained by employing SPtrTT7 $(12.6 \mathrm{mg} / \mathrm{L})$ revealed that HpaBC has lower conversion efficiency than that of SptrTT7 (Fig. 2B). Since plant P450s are generally difficult to be functionally expressed in bacterial hosts such as E. coli, these results suggest that engineering the signal peptide of plant P450s can be an effective solution for bacterial production of diverse natural products requiring plant $\mathrm{P} 450 \mathrm{~s}$.

To complete the de novo biosynthetic pathway for DHQ production, the $F 3 H$ gene was inserted into the previously constructed pNRG plasmid, resulting in pDHK. Plasmids pDHK and $\mathrm{pDHQ}$ were introduced into the $p$-coumaric acid producer (BTY5 harboring pCOU), resulting in the DHQ strain. Shake flask culture of the DHQ strain in MR medium supplemented with $20 \mathrm{~g} / \mathrm{L}$ of glycerol and $2 \mathrm{~g} / \mathrm{L}$ of yeast extract resulted in $20.1 \mathrm{mg} / \mathrm{L}$ of DHQ production. Glycerol was used as the carbon source because higher production of naringenin, the precursor to DHQ, was achieved from glycerol when compared to that achieved from glucose in our previous study (Yang et al., 2018). Production of DHQ was confirmed by LCMS analysis (Fig. 1D).

Next, fed-batch fermentation was performed to test the performance of the DHQ strain in bioreactors. The DHQ strain was fed-batch cultured in R/2 medium supplemented with 20 

This represents the first demonstration of de novo production of DHQ from simple carbon sources in E. coli.

\section{Conclusions}

In this study, an E. coli strain capable of producing an important phenylpropanoid DHQ from glycerol was developed. The DHQ strain was developed based on the previously constructed $p$-coumaric acid overproducer, achieving $239.4 \mathrm{mg} / \mathrm{L}$ of DHQ production after optimizing the biosynthetic pathway and engineering the N-terminal signal peptide of a plantderived P450. To the best of our knowledge, this is the first report on one-step production of DHQ in E. coli. These results also represent the highest titer of DHQ obtained in E. coli. Although higher titers might be obtained by stepwise culture, switching from a multistep process (stepwise culture) to a single step process (one-step de novo production) is important. This is because employing a single microbial strain is much simpler, making the process more economical, less laborious, and time-saving. This would lead to higher overall yield and productivity. The metabolic engineering and process optimization strategies employed in this study is generally applicable for the production of complex natural products, particularly those requiring multiple precursors. Microbial cell factories developed using such strategies will enable robust and sustainable production of important natural products, significantly come. 
Research Foundation of Korea.

301

302

Author contributions

S.Y.L. conceived the project, S.Y.P., D.Y., S.H.H., and S.Y.L. designed the final manuscript.

307

Declarations of interest 
A<smiles>O=C1C[C@H](c2ccc(O)cc2)Oc2cc(O)cc(O)c21</smiles>

Naringenin<smiles>O=C(O)C1C(=O)c2c(O)cc(O)cc2OC1c1ccc(O)cc1</smiles>

DHK

C<smiles>O=C1C[C@H](c2ccc(O)cc2)Oc2cc(O)cc(O)c21</smiles>

Naringenin

F3H

SPtrTT7/ATR2<smiles>O=C1c2c(O)cc(O)cc2O[C@H](c2ccc(O)c(O)c2)C1O</smiles>

DHQ
B
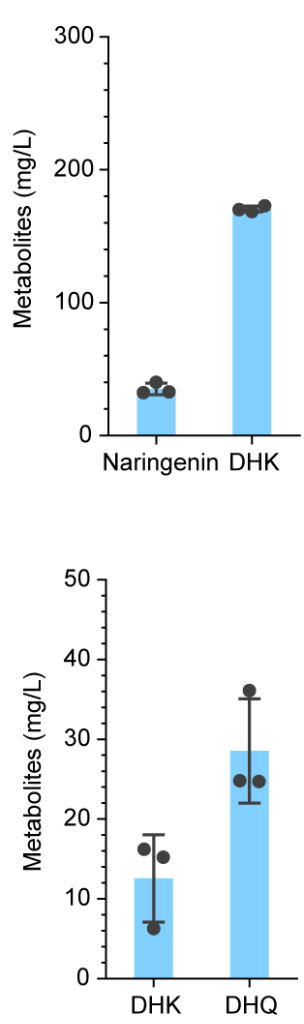

D

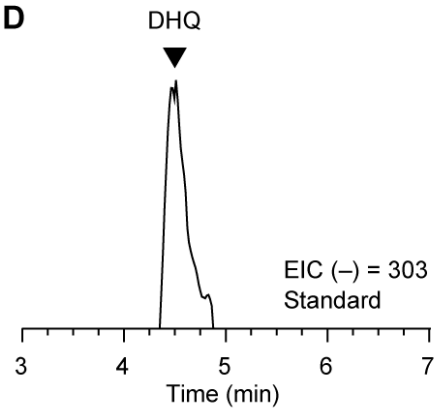

$\operatorname{EIC~}(-)=303$ Sample

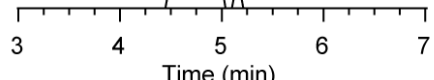<smiles>O=C1C[C@H](c2ccc(O)cc2)Oc2cc(O)cc(O)c21</smiles>

$\downarrow \stackrel{\text { TT7/ATR2 from } A \text {. thaliana }}{\text { TH }}$<smiles>O=C1C[C@H](c2ccc(O)c(O)c2)Oc2cc(O)cc(O)c21</smiles>

Eriodictyol

E
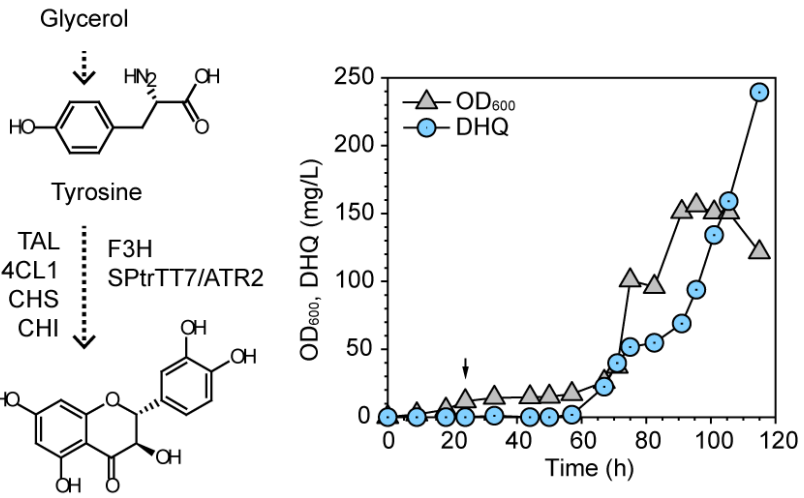

DHQ

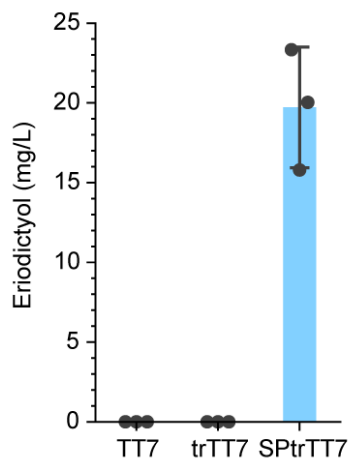

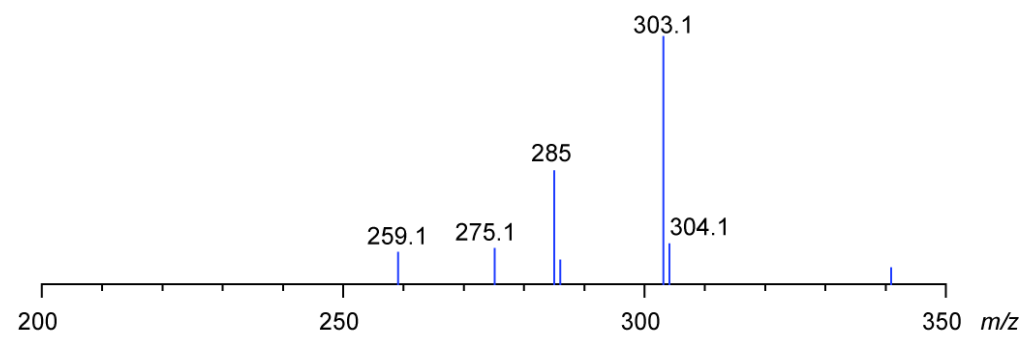

Fig. 1. Production of DHQ. (A) Conversion of naringenin to DHK by F3H from A. thaliana.

(B) Engineering TT7 for conversion of naringenin to eriodictyol. trTT7, a TT7 variant with its 
315 N-terminal signal peptide truncated; SPtrTT7, a TT7 variant with its N-terminal signal peptide

316 exchanged with that of E. coli OmpA. (C) Conversion of naringenin to DHQ by F3H and

317 SPtrTT7. Residual DHK is also shown. (D) Fed-batch fermentation profile of the DHQ strain

318 in R/2 medium. Arrow in the graph indicates IPTG induction time point. (E) Extracted ion

319 chromatograms (EICs) and mass spectrums of DHQ generated by LC-MS, from the authentic

320 standard (upper panels) or from the culture sample of the DHQ strain (lower panels). Data are

321 representative of three independent replicates. (A-C) Error bars, mean $\pm \mathrm{SD}(n=3)$. 
A

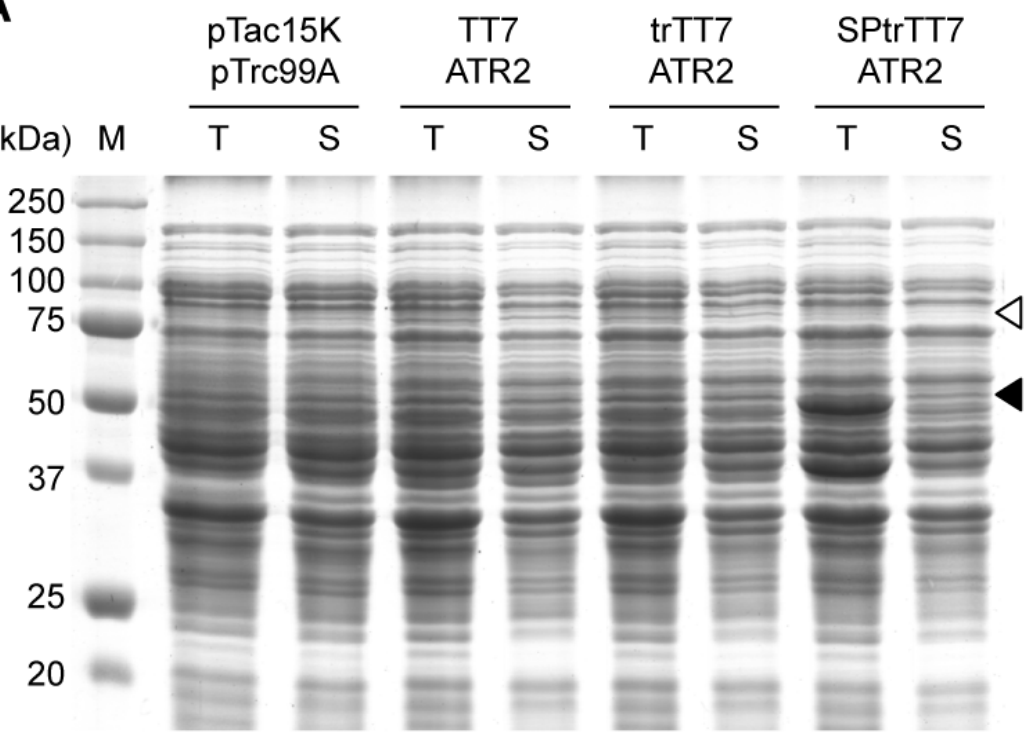

Fig. 2. Production of DHQ. (A) SDS-PAGE analysis of E. coli BL21(DE3) strains harboring pTac15K-derived plasmids harboring the noted TT7 variants (pTac15K denotes the control without TT7) and pTrc99A-derived plasmids harboring ATR2 (pTrc99A denotes the control without ATR2). T, total fraction; S, soluble fraction; M, protein size marker. Empty triangle denotes ATR2 expression; black triangle denotes TT7 variants expression. (B) Conversion of naringenin to DHQ when hpaBC was employed instead of TT7 and ATR2. Residual DHK is also shown. Error bars, mean $\pm \mathrm{SD}(n=3)$. 
Table 1. List of strains used in this study.

\begin{tabular}{|c|c|c|}
\hline Name & Description & Source \\
\hline DH5 $\alpha$ & $\begin{array}{l}\mathrm{F}^{-} \varphi 80 \text { lacZAM15 } \triangle(\text { lacZYA- } \\
\operatorname{argF}) \mathrm{U} 169 \text { recAl endA1 hsdR17 }\left(r_{K}^{-},\right. \\
\left.m_{K}^{+}\right) \text {phoA supE44 thi-1 gyrA96 relA1 } \lambda^{-}\end{array}$ & Invitrogen \\
\hline BL21(DE3) & $\mathrm{F}^{-}$ompT hsdSB (rB-mB-) gal dcm (DE3) & Invitrogen \\
\hline BTY5 & BL21 (DE3) $\Delta t y r R \Delta t y r P$ & $\begin{array}{l}\text { (Kim et al., } \\
2018 \text { ) }\end{array}$ \\
\hline BTY5.13 & BTY5 harboring pTY13 & $\begin{array}{l}\text { (Kim et al., } \\
\text { 2018) }\end{array}$ \\
\hline DHQ & BTY5 harboring pCOU, pDHK, and pDHQ & This study \\
\hline
\end{tabular}

333 
Table 2. List of plasmids used in this study. Abbreviations: Ap, ampicillin; Km, kanamycin;

Cm, chloramphenicol; Spc, spectinomycin; R, resistance.

\begin{tabular}{|c|c|c|}
\hline Name & Description & Source \\
\hline pBBR1TaC & $\mathrm{Cm}^{\mathrm{R}}$, tac promoter, $\mathrm{pBBR} 1$ origin, $4.7 \mathrm{~kb}$ & $\begin{array}{l}\text { (Yang et al., } \\
2018 \text { ) }\end{array}$ \\
\hline pBBR1T7 & $\begin{array}{l}\text { pBBR1Tac derivative, of which promoter was changed from } t a c \\
\text { to } \mathrm{T} 7,4.7 \mathrm{~kb}\end{array}$ & This study \\
\hline $\mathrm{pET}-30 \mathrm{a}(+)$ & $\mathrm{Km}^{\mathrm{R}}, T 7$ promoter, ColE1 origin, $l a c \mathrm{I}^{\mathrm{q}}, 5.4 \mathrm{~kb}$ & Novagen \\
\hline pTac15K & $\mathrm{Km}^{\mathrm{R}}, t a c$ promoter, $\mathrm{p} 15 \mathrm{~A}$ origin, $4.0 \mathrm{~kb}$ & $\begin{array}{l}\text { (Lee et al., } \\
2008)\end{array}$ \\
\hline pTrc99A & $\mathrm{Ap}^{\mathrm{R}}, \operatorname{trc}$ promoter, pBR322 (ColE1) origin, $l a c \mathrm{I}^{\mathrm{q}}, 4.2 \mathrm{~kb}$ & $\begin{array}{l}\text { (Lee et al., } \\
2008 \text { ) }\end{array}$ \\
\hline $\mathrm{pTrcCDFS}$ & $\mathrm{Spc}^{\mathrm{R}}, \operatorname{trc}$ promoter, $\mathrm{CDF}$ origin, $\operatorname{lac} \mathrm{I}^{\mathrm{q}}, 3.7 \mathrm{~kb}$ & This study \\
\hline pCDFDuet-1 & $\mathrm{Spc}^{\mathrm{R}}, T 7$ promoter, $\mathrm{CDF}$ origin, $l a c \mathrm{I}^{\mathrm{q}}, 3.8 \mathrm{~kb}$ & Novagen \\
\hline pRSFDuet-1 & 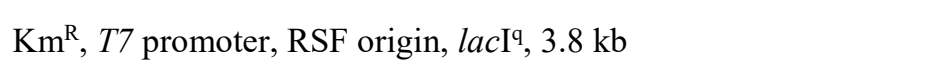 & Novagen \\
\hline pET-30a (+)-hpaBC & pET-30a $(+)$ derivative containing $h p a B C$ from $E$. coli & This study \\
\hline pCAF & pTacCDFS derivative containing $h p a B C$ from $E$. coli & This study \\
\hline pTac15K-F3H & pTac15K derivative containing $F 3 H$ from $A$. thaliana & This study \\
\hline pTrc99A-TT7 & pTrc99A derivative containing $T T 7$ from $A$. thaliana & This study \\
\hline pTrc99A-trTT7 & $\begin{array}{l}\text { pTrc99A derivative containing N-terminal signal peptide- } \\
\text { truncated } T T 7 \text { (trTT7) from } A \text {. thaliana }\end{array}$ & This study \\
\hline pTrc99A-SPtrTT7 & $\begin{array}{l}\text { pTrc99A derivative containing } A \text {. thaliana } T T 7 \text { with its } \mathrm{N}- \\
\text { terminal signal peptide exchanged with } E \text {. coli OmpA signal } \\
\text { peptide (SPtrTT7) }\end{array}$ & This study \\
\hline pTac15K-ATR2 & pTac15K derivative containing $A T R 2$ from $A$. thaliana & This study \\
\hline $\mathrm{pDHQ}$ & pTrc99A derivative containing $A$. thaliana ATR2 and SPtrTT7 & This study \\
\hline pDHQ2 & pBBR1TaC derivative containing A. thaliana ATR 2 and SPtrTT7 & This study \\
\hline pNRG & $\begin{array}{l}\text { pTrcCDFS derivative containing mutated } 4 C L 1 \text { from } A \text {. thaliana } \\
(4 C L 1 m ; \mathrm{I} 250 \mathrm{~L} / \mathrm{N} 404 \mathrm{~K} / \mathrm{I} 461 \mathrm{~V}), C H I \text { from } A \text {. thaliana and } C H S \\
\text { from Petunia } x \text { hybrida }\end{array}$ & $\begin{array}{l}\text { (Yang et al., } \\
\text { 2018) }\end{array}$ \\
\hline $\mathrm{pDHK}$ & pNRG derivative additionally containing $A$. thaliana $F 3 H$ & This study \\
\hline $\mathrm{pCOU}$ & $\begin{array}{l}\text { pTac15K derivative containing tyrC from Zymomonas mobilis } \\
\text { under trc promoter, aroG } G^{\mathrm{fbr}} \text { and } \text { aroL from E. coli } \mathrm{K} 12 \text { under tac } \\
\text { promoter, and poly-His-tagged TAL from S. espanaensis under a } \\
\text { separate } t r c \text { promoter }\end{array}$ & $\begin{array}{l}\text { (Yang et al., } \\
\text { 2018) }\end{array}$ \\
\hline
\end{tabular}


Table 3. List of oligonucleotides used in this study.

\begin{tabular}{ll}
\hline Name & Sequence (5'-3')* \\
\hline hpaB_F_NdeI & agagagcatatgaaaccagaagatttccgcg \\
hpaB_R_over & cattatatctccttcttaaagttaattatttcagcagcttatccagcatg \\
hpaC_F_over & ttaactttaagaaggagatataatgcaattagatgaacaacgcctg \\
hpaC_R_BamHI & agagagggatccttaaatcgcagcttccatttc \\
hpaBC_F_EcoRI & gaaacagaattcatgaaaccagaagatttccgc \\
hpaBC_R_BamHI & ctctagaggatccccgggtaccattaaatcgcagcttccatttc \\
F3H_F_EcoRI & agagagaattcttaactttaagaaggagatataatggctccaggaactttgactg \\
F3H_R_SacI & agacaggagctcctaagcgaagatttggtcgac \\
pTrc_PstI_Gib_R & caaaacagccaagcttgcatgcctgcag \\
TT7_F_BamHI & agacagggatcctttcacacaggaaacagaccatggctactctgtttctgac \\
TT7_R_SalI & agacaggtcgacttagccactgcccagc \\
trTT7_F_BamHI & agacagggatcctttcacacaggaaacagaccatgtcccatcgccgcaac \\
TT7_R_XbaI & agacagtctagattagccactgcccag \\
SP_F1_BamHI & agacagggatcctttcacacaggaaacagaccatgaaaaagacagctatcgcgattgcagt \\
gecactggctg & gcagtggcactggctggtttcgctaccgtagcgcaggcctcccatcgccgcaac \\
SP_F2_over & agacaggaattcttcacacaggaaacaatgtcttcttcttcttcttc \\
ATR2_F_EcoRI & agacagggatccttaccacacatcacgaagat \\
ATR2_R_BamHI & agacaggagctctttcacacaggaaacagaccatgtcttcttcttcttcttc \\
ATR2_F_SacI & cctctagaaataattttgtttaactttaagaaggagatatacattctagagtcgacctgcaggca \\
pBBR1T7_IV_F & tg \\
pBBR1T7_IV_R & ggaattgttatccgctcacaattccctatagtgagtcgtattagcctgaataagtgataataag \\
pBBR1_frag_F & cttattatcacttattcaggctaatacgactcactataggg \\
pBBR1_IV_F & caaaacagccaagcttgcatgcaagcttgtcgacggagctcg \\
pBBR1_IV_R & gcatgcaagcttggctgttttg \\
\hline
\end{tabular}

*Underlines denote restriction sites. 


\section{References}

An, S. M., Kim, H. J., Kim, J. E., Boo, Y. C., 2008. Flavonoids, taxifolin and luteolin attenuate cellular melanogenesis despite increasing tyrosinase protein levels. Phytother. Res. 22, 1200-1207.

Bijak, M., 2017. Silybin, a major bioactive component of Milk Thistle (Silybum marianum L. Gaernt.)-Chemistry, bioavailability, and metabolism. Molecules. 22, doi: 10.3390/molecules22111942.

Deep, G., Oberlies, N. H., Kroll, D. J., Agarwal, R., 2007. Isosilybin B and isosilybin A inhibit growth, induce G1 arrest and cause apoptosis in human prostate cancer LNCaP and 22Rv1 cells. Carcinogenesis. 28, 1533-1542.

Dey, T. B., Chakraborty, S., Jain, K. K., Sharma, A., Kuhad, R. C., 2016. Antioxidant phenolics and their microbial production by submerged and solid state fermentation process: A review. Trends Food Sci. Technol. 53, 60-74.

Galanie, S., Thodey, K., Trenchard, I. J., Interrante, M. F., Smolke, C. D., 2015. Complete biosynthesis of opioids in yeast. Science. 349, 1095-1100.

Gazak, R., Walterova, D., Kren, V., 2007. Silybin and silymarin - New and emerging applications in medicine. Curr. Med. Chem. 14, 315-338.

Gibson, D. G., Young, L., Chuang, R. Y., Venter, J. C., Hutchison, C. A., Smith, H. O., 2009. Enzymatic assembly of DNA molecules up to several hundred kilobases. Nat Methods. 6, 343-U341.

González-Flecha, B., Demple, B., 1995. Metabolic sources of hydrogen peroxide in aerobically growing Escherichia coli. J. Biol. Chem. 270, 13681-13687.

Imlay, J. A., Linn, S., 1986. Bimodal pattern of killing of DNA-repair-defective or anoxically grown Escherichia coli by hydrogen peroxide. J. Bacteriol. 166, 519-527.

Jones, J. A., Collins, S. M., Vernacchio, V. R., Lachance, D. M., Koffas, M. A. G., 2016b. Optimization of naringenin and $p$-coumaric acid hydroxylation using the native $E$. coli hydroxylase complex, HpaBC. Biotechnol. Prog. 32, 21-25.

Kim, B., Binkley, R., Kim, H. U., Lee, S. Y., 2018. Metabolic engineering of Escherichia coli for the enhanced production of 1-tyrosine. Biotechnol. Bioeng. 115, 2554-2564.

Lee, S. B., Cha, K. H., Selenge, D., Solongo, A., Nho, C. W., 2007. The chemopreventive effect of taxifolin is exerted through ARE-dependent gene regulation. Biol. Pharm. Bull. 30, 1074-1079.

Luo, X. Z., Reiter, M. A., d'Espaux, L., Wong, J., Denby, C. M., Lechner, A., Zhang, Y. F., Grzybowski, A. T., Harth, S., Lin, W. Y., Lee, H., Yu, C. H., Shin, J., Deng, K., Benites, V. T., Wang, G., Baidoo, E. E. K., Chen, Y., Dev, I., Petzold, C. J., Keasling, J. D., 2019. Complete biosynthesis of cannabinoids and their unnatural analogues in yeast. Nature. 567, 123-126.

Lv, Y. K., Gao, S., Xu, S., Du, G. C., Zhou, J. W., Chen, J., 2017. Spatial organization of silybin biosynthesis in milk thistle [Silybum marianum (L.) Gaertn]. Plant J. 92, 9951004. 
Lv, Y. K., Marsafari, M., Koffas, M., Zhou, J. W., Xu, P., 2019a. Optimizing oleaginous yeast cell factories for flavonoids and hydroxylated flavonoids biosynthesis. ACS Synth. Biol. $8,2514-2523$.

Lv, Y. K., Xu, S., Lyu, Y. B., Zhou, S. H., Du, G. C., Chen, J., Zhou, J. W., 2019b. Engineering enzymatic cascades for the efficient biotransformation of eugenol and taxifolin to silybin and isosilybin. Green Chem. 21, 1660-1667.

Mengs, U., Pohl, R. T., Mitchell, T., 2012. Legalon(R) SIL: the antidote of choice in patients with acute hepatotoxicity from amatoxin poisoning. Curr. Pharm. Biotechnol. 13, 19641970.

Niu, G. Q., Zhao, S., Wang, L., Dong, W., Liu, L., He, Y. K., 2017. Structure of the Arabidopsis thaliana NADPH-cytochrome P450 reductase 2 (ATR2) provides insight into its function. FEBS J. 284, 754-765.

Owens, D. K., Crosby, K. C., Runac, J., Howard, B. A., Winkel, B. S. J., 2008. Biochemical and genetic characterization of Arabidopsis flavanone 3b-hydroxylase. Plant Physiol. Biochem. 46, 833-843.

Park, S. Y., Binkley, R. M., Kim, W. J., Lee, M. H., Lee, S. Y., 2018. Metabolic engineering of Escherichia coli for high-level astaxanthin production with high productivity. Metab. Eng. 49, 105-115.

Razak, S., Afsar, T., Ullah, A., Almajwal, A., Alkholief, M., Alshamsan, A., Jahan, S., 2018. Taxifolin, a natural flavonoid interacts with cell cycle regulators causes cell cycle arrest and causes tumor regression by activating Wnt/beta-catenin signaling pathway. BMC Cancer. 18, 1043.

Sambrook, J., E. F. Fritsch, and T. Maniatis., 1989. Molecular Cloning: A Laboratory Manual (Cold Spring Harbor Laboratory, Cold Spring Harbor, NY 1982).

Sato, M., Murakami, K., Uno, M., Ikubo, H., Nakagawa, Y., Katayama, S., Akagi, K., Irie, K., 2013. Structure-activity relationship for (+)-taxifolin isolated from silymarin as an inhibitor of amyloid beta aggregation. Biosci. Biotechnol. Biochem. 77, 1100-1103.

Schoenbohm, C., Martens, S., Eder, C., Forkmann, G., Weisshaar, B., 2000. Identification of the Arabidopsis thaliana flavonoid 3'-hydroxylase gene and functional expression of the encoded P450 enzyme. Biol. Chem. 381, 749-753.

Srinivasan, P., Smolke, C. D., 2020. Biosynthesis of medicinal tropane alkaloids in yeast. Nature. 585, 614-619.

Sunil, C., Xu, B., 2019. An insight into the health-promoting effects of taxifolin (dihydroquercetin). Phytochemistry. 166, 112066.

Yang, D., Kim, W. J., Yoo, S. M., Choi, J. H., Ha, S. H., Lee, M. H., Lee, S. Y., 2018. Repurposing type III polyketide synthase as a malonyl-CoA biosensor for metabolic engineering in bacteria. Proc. Natl. Acad. Sci. U. S. A. 115, 9835-9844.

Yang, D., Park, S. Y., Park, Y. S., Eun, H., Lee, S. Y., 2020a. Metabolic engineering of Escherichia coli for natural product biosynthesis. Trends Biotechnol. 38, 745-765. 